\title{
El Estado y la vulnerabilidad ante la violencia
}

\author{
Frida Carolina Barrios Medina`
}

doi: http://dx.doi.org/10.32870/espiral.v26i74.7011.g6164

La conexión entre Estado y violencia, tal como figura en el título del libro aquí reseñado, es parte esencial de la definición de Estado que brindan los textos clásicos de la teoría política. Max Weber, basándose en el Leviatán de Hobbes, establece el uso de la violencia como un medio legítimo para garantizar la paz entre los hombres. Por otra parte, la visión contractual del Estado se construye a partir de otros autores, como John Locke y su concepto de sociedad política, o Rousseau, quien establece el Estado social.

Para estos autores, se construye una relación entre la violencia, en sus distintas formas, y las instituciones que derivan del orden estatal, de tal forma que el Estado ejerce violencia de manera consensuada entre los ciudadanos. Sin embargo, en los últimos años en América Latina, la creciente violencia proveniente de la delincuencia organizada ha colapsado a las instituciones del Estado, y la población se halla vulnerable ante los asesinatos, secuestros y la delincuencia en general. En México, el papel del Estado para garantizar la paz en la visión contractual, por tanto, no se cumple en

José Luis Cisneros, José Luis Estrada Rodríguez, y Pedro José Peñaloza (coords.) (2017). Estado y violencia. Rasgos y rostros. México: Porrúa. 
el escenario actual, lo cual deslegitima a las instituciones encargadas de la seguridad pública y en general al Estado en el país.

Esta problemática se aborda de manera detallada, precisa y abierta en el libro aquí reseñado. Los autores son académicos que contribuyen al debate contemporáneo sobre las organizaciones sociales y las instituciones creadas para el control y el orden social.

El libro establece una relación directa entre la ausencia del Estado o su vulnerabilidad y la violencia como mecanismo de control hacia la población por parte de las bandas del crimen organizado. Es un magnífico documento que adopta una visión regional. Compuesto por trece capítulos, sus autores destacan cómo el narcotráfico se inserta como un actor capaz de generar violencia creciente por el control del territorio en toda América Latina, así como de competir con los Estados-nación por el poder. Se construye la hipótesis de que es preciso contar con un rediseño del Estado porque el pacto social que suscribía el mismo con los ciudadanos se modificó con el paso de modelo del Estado benefactor al Estado de exclusión social.

En el 2016, la Open Society Foundation presentó el informe Atrocidades innegables. Confrontando crímenes de lesa humanidad en México, en el que, con expertos de la sociedad civil, documentó la crisis de seguridad, las desapariciones, la tortura y la violencia ejercida por el Estado mexicano en la llamada guerra contra el narcotráfico. En este panorama nacional, los delincuentes son los enemigos del Estado, pero se confunden entre el gran cúmulo de inocentes que han sido abatidos por las fuerzas del orden. La sociedad está en riesgo, tanto ante el crimen organizado como ante la violencia legítima que se ejerce a partir del modelo económico, la exclusión social y el control de la sociedad por medio del castigo. Aportando en este tenor, el libro aquí reseñado recorre la violencia atribuida al Estado,

\section{6}


y describe las ejecuciones extrajudiciales como mecanismo incivilizatorio de la sociedad.

Es decir, con las reformas neoliberales producto del llamado consenso de Washington, las políticas públicas en México se han centrado en un Estado mínimo, con el mismo modelo aplicado en los países de Hispanoamérica. Esto ha producido ausencia de Estado y carencia del control sobre todas las acciones de los ciudadanos, lo cual ha dado lugar al surgimiento de nuevos actores, otras fuerzas que proveen satisfactores y servicios y ejercen el poder, mientras que al mismo tiempo vulneran la democracia, los derechos humanos y, por supuesto, el desarrollo social, económico y político de los países. Bailey (2014) sostiene que en el caso de México hay una fuerte crisis en los aparatos de justicia, en las instituciones encargadas de velar por los derechos y otorgar certidumbre a la vida de las personas, esto producto de la corrupción y colusión de las autoridades con el crimen organizado.

Este panorama vuelve continua la relación entre el Estado y la violencia, a lo que se suma incluso la inacción de las instituciones encargadas de preservar el orden, lo que contribuye a lo que Beck (2006) denomina sociedad del riesgo, en la que la inestabilidad, el descontrol y la incertidumbre se convierten en elementos principales.

Los autores del libro sostienen que el desempleo en los países en desarrollo se constituye como uno de los principales elementos que alimenta al crimen organizado, y también relatan experiencias sobre los actores no estatales que se hallan inmersos en la violencia como forma de control, dominación y usufructo económico. A esto se une la forma en que, en el contexto histórico de México, el Estado era un aglutinador de masas, construía un modelo de vida e integraba a las distintas capas sociales para su control. A partir de la globalización, las nuevas tecnologías y el auge del capitalismo voraz, el Estado se ha alejado simbólica- 
mente de los ciudadanos, sus expectativas y necesidades, lo que ha generado nuevos ciudadanos, individuales, con una sociedad fragmentada en lo familiar e institucional.

Byung-Chun (2014) retoma este aspecto de los ciudadanos como entes individuales, y sostiene que existe un choque social, producto del desinterés de las instituciones por los individuos, pues no se propicia la relación entre el Gobierno y los ciudadanos, sino que se establece un sistema de ausencia entre los sujetos, sólo unidos a través de las redes sociales pero vulnerables ante el crimen organizado. Esto se debe a que las instituciones también se formaron para el sostenimiento del régimen político, alejadas de las demandas sociales y contribuyendo poco al fomento de la justicia y la seguridad como valores. La autoseguridad, así como el autocuidado en materia de salud, se han generado para disminuir la incidencia del Estado en la sociedad, para transformar al Estado en un aparato débil, al que Fukuyama (2004) se refiere como incapaz institucionalmente para garantizar el orden.

Esto entra en diálogo con la obra aquí reseñada, pues en ella se muestra cómo hay un resquebrajamiento en la legitimidad del Estado en México, esto evidenciado en la participación de las fuerzas de seguridad en los casos de Tlatlaya, en el Estado de México, Apatzingán y Tanguato, en Michoacán, Nochixtlán, en Oaxaca, y otros, en los cuales han existido evidencias del abuso en el uso de la fuerza y de la participación de los militares en ejecuciones extrajudiciales, lo que también sucedió en el caso de los estudiantes normalistas desaparecidos en Ayotzinapa, Guerrero, el 27 de septiembre de 2014, un caso que incluso atrajo la mirada internacional y, por supuesto, mostró a un Estado incapaz de actuar ante la violencia promovida por los grupos del crimen organizado.

Entre los elementos que se destacan del análisis que realizan los investigadores, está el cuestionamiento de la 
capacidad del Estado para brindar orden y seguridad en ciertos territorios en los que la ausencia de un Estado de derecho ha orillado a los ciudadanos a conformar autodefensas, en el caso de Michoacán, y policías comunitarias, en el caso de Guerrero.

El enorme mérito de Estado y violencia. Rasgos y rostros es que se anima a cruzar la línea que separa los campos del conocimiento que estudian la violencia y el Estado. También es altamente meritorio de este libro que inserta la discusión sobre cómo se construye la violencia, en términos conceptuales, y cómo otorga identidad a las acciones de los individuos. La violencia por parte de los grupos del crimen organizado tiene un objetivo material y simbólico: obtener dinero de las personas a las cuales intimida, domina y controla, pero también existe violencia social producto de las desigualdades que construye el capitalismo, por las cuales la ausencia de posesiones, capital humano y educación genera una masa de desposeídos, fuera del sistema social, excluidos de los cuales el Estado no se responsabiliza. Los migrantes forman otro grupo cuyos derechos no reconoce el Estado, por su situación de tránsito. Y todo esto revisa el libro reseñado.

Si bien el trabajo colectivo que se reseña habla del Estado y la violencia que se ha incrementado con el crimen organizado en México, también describe cómo la violencia es un elemento ineludible de las sociedades contemporáneas. La violencia social, la de género y ahora también la violencia política están entre sus múltiples formas, de las cuales son crecientes sus manifestaciones en el comportamiento social, como los feminicidios. El libro detalla, a partir de una descripción tan minuciosa como alarmante, los datos existentes sobre víctimas de feminicidio y de violencia contra las mujeres.

La violencia, como señala el material, tiene rostros en las estadísticas y en los datos que pueden consultarse en múl- 
tiples fuentes, como la Encuesta nacional de victimización y percepción sobre seguridad pública (ENVIPE) (Instituto Nacional de Estadística y Geografía, 2017). En esa fuente en concreto, se exponen datos alarmantes: en 2016, el 34.2\% de los hogares en México fue víctima de algún delito, es decir, 11.68 millones de hogares, cifra mayor a los 11.36 millones registrados en el 2015. El deterioro de las instituciones está presente en la problemática cuando se señala que en el mismo año sólo el 9.7\% de los delitos fue denunciado.

Los autores del libro se manifiestan a favor de un Estado fuerte, el cual no necesariamente debe ser represor y autoritario. Explican cómo el Estado debe transformarse para construir uno de derecho, con participación ciudadana, promotor de la gobernanza y legitimado por sus políticas públicas. Plantean dentro de sus argumentos, coincidentemente con el antropólogo Marvin Harris (1981), que el contexto social determina la violencia: la escasez genera la pugna entre los distintos grupos sociales, y a su vez promueve la competencia, situación en la que el Estado debe ser capaz de controlar la ambición y la conducta de los sujetos.

Por tanto, el papel del Estado vuelve a ser el nudo gordiano sobre el cual inevitablemente se vuelve para justificar su propio rol como represor y garante de la paz a través de la guerra, la violencia y el control subjetivo de los cuerpos. Por tanto, el libro aspira a presentar evidencias que vinculan inevitablemente al Estado con la violencia y cuya discusión está vigente, esto mediante un recorrido súbito por los hechos que viven los ciudadanos de manera cotidiana en el país, como secuestros, extorsiones y pérdida de integración social. Además, con estos planteamientos esgrimidos, se abre una agenda de investigación que considera al Estado como uno de los elementos cambiantes en el contexto histórico por sus alcances y limitaciones ante el crimen organizado. 
El trabajo de Estado y violencia... contribuye a una nueva comprensión de las dimensiones de la violencia en sus distintas formas, pero también al análisis de las modificaciones que ha tenido el Estado en su devenir histórico. Involucrar al Estado para una mejor comprensión de los fenómenos de violencia es un avance notable con miras al desarrollo de mejores políticas públicas de seguridad que busquen tanto bajar los indicadores de criminalidad como subir los indicadores de mejor desempeño y efectividad del Estado.

Bailey,J.(20I4). Crimen e impunidad: las trampas de la seguridad Bibliografía en México. México: Debate.

Beck, U. (2006). La sociedad del riesgo: hacia una nueva modernidad. Barcelona: Paidós Iberoamérica.

Byung-Chun, H. (20 I4). Psicopolítica. Neoliberalismo y nuevas técnicas de poder. Barcelona: Herder.

Instituto Nacional de Estadística y Geografía (2017). Encuesta nacional de victimización y percepción sobre seguridad pública. México: INEGI.

Fukuyama, F. (2004). La construcción del Estado. Hacia un nuevo orden mundial en el siglo XXI. Barcelona: Ediciones B.

Harris, M. ( $198 \mathrm{I}$ ). Vacas, cerdos, guerras y brujas. Los enigmas de la cultura. Madrid:Alianza. 